\title{
Salidroside Protects against MPP+-Induced Neuronal Injury through DJ-1-Nrf2 Antioxidant Pathway
}

\author{
Leitao Wu, ${ }^{1}$ Hang Xu, ${ }^{2}$ Liang Cao, ${ }^{3}$ Tao Li, ${ }^{1}$ Ruru Li, ${ }^{1}$ Yang Feng, \\ Jianzong Chen, ${ }^{1}$ and Jing $\mathrm{Ma}^{3}$ \\ ${ }^{1}$ Research Center of Traditional Chinese Medicine, Xijing Hospital, Fourth Military Medical University, Xian 710032, China \\ ${ }^{2}$ Department of Pharmacy, Xijing Hospital, Fourth Military Medical University, 169 West Changle Road, Xian 710032, China \\ ${ }^{3}$ Department of Chinese Medicine, Xijing Hospital, Fourth Military Medical University, 169 West Changle Road, Xi'an 710032, China \\ Correspondence should be addressed to Jianzong Chen; jzchen57@fmmu.edu.cn and Jing Ma; jingma@fmmu.edu.cn
}

Received 26 April 2017; Accepted 25 July 2017; Published 28 September 2017

Academic Editor: Gunhyuk Park

Copyright (C) 2017 Leitao Wu et al. This is an open access article distributed under the Creative Commons Attribution License, which permits unrestricted use, distribution, and reproduction in any medium, provided the original work is properly cited.

\begin{abstract}
Parkinson's disease (PD) is the second most common neurodegenerative disorder. We have found that salidroside (Sal) exhibited neuroprotective effects against MPP+ toxicity. However, the molecular mechanism is not fully understood. In this study, we found that Sal significantly prevented MPP+-induced decrease of mRNA and protein expression of Nrf2, GCLc, SOD1, and SOD2 in SH-SY5Y cells. Moreover, silencing of Nrf2 significantly inhibited Sal-induced increase in mRNA and protein expression of GCLc, SOD1, and SOD2. But Nrf2 silence did not significantly impact Sal-exhibited effects on DJ-1 expression. Silencing of Nrf2 significantly suppressed the decrease of apoptosis induced by Sal in MPP+-treated SH-SY5Y cells. Sal significantly prevented MPP+induced decrease of the mRNA and protein expression of DJ-1 in SH-SY5Y cells. Moreover, silencing of DJ-1 significantly inhibited Sal-induced increase in mRNA and protein expression of Nrf2, GCLc, SOD1, and SOD2 in MPP+-treated SH-SY5Y cells. These results indicated that DJ-1 was an upstream regulator of Nrf2 in the neuroprotective effects of Sal. Furthermore, silencing of DJ-1 significantly suppressed the decrease of apoptosis induced by Sal in MPP+-treated SH-SY5Y cells. In conclusion, Sal prevented $\mathrm{MPP}+$-induced neurotoxicity through upregulation of DJ-1-Nrf2-antioxidant pathway. Our findings provide novel insights into the neuroprotective effects of Sal against PD.
\end{abstract}

\section{Introduction}

Parkinson's disease (PD) is the second most common neurodegenerative disorder, affecting more than $1 \%$ of humans over 60 years of age $[1,2]$. PD is attributed to loss of dopaminergic (DA) neurons in the substantia nigra pars compacta $(\mathrm{SNpc})$ and characterized by the presence of ubiquitinated alpha-synuclein- ( $\alpha$-syn-) containing cytoplasmic inclusions called Lewy bodies in surviving SNpc neurons $[3,4]$. Although the accurate mechanism of PD is not known, oxidative injury and associated apoptotic cell death are believed to play an important role $[2,5,6]$. Large quantity of studies has shown that antioxidant intervention is effective for the treatment of PD and other neurodegenerative diseases [6]. However, clinical therapy of PD is limited by shortage of validated drugs $[7,8]$.

Salidroside (p-hydroxyphenethyl-b-D-glucoside; C14H20O7) (Sal) is a major component extracted from Rhodiola rosea
L., which is a plant popular in traditional medicine in Asian and Eastern European countries (Figure 1(a)). It is shown that Sal possesses a variety of pharmacological activities, including antioxidant, antiaging, antitumor, antihypoxic and neuroprotective effects [9-13]. Our previous studies have shown that Sal protects against apoptosis in SH-SY5Y cells by inhibiting the NO pathway [14]. We also show that Sal protects against $\mathrm{PD}$ in mouse model through ROS-NOrelated mitochondrion pathway [15]. These results suggest that the antioxidant activity of Sal plays a pivotal role in the neuroprotective effects against PD. However, the mechanism underlying the neuroprotective effects of Sal is still far from being completely understood.

MPTP- (1-methyl-4-phenyl-1,2,5,6- tetrahydropyridine-) induced neuronal injury in neuron cells and neurodegenerative disorder in animals are usually used for the study 


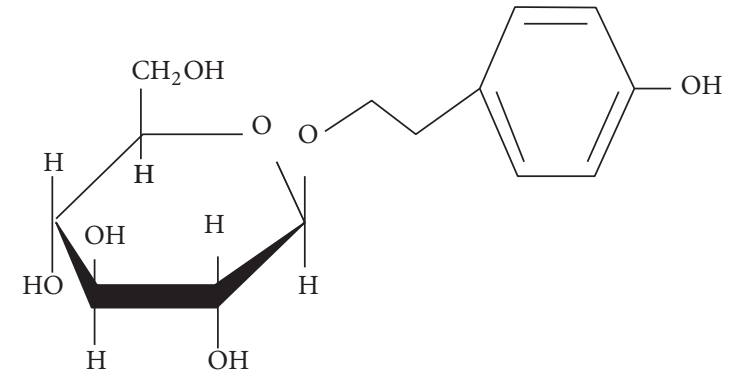

(a)

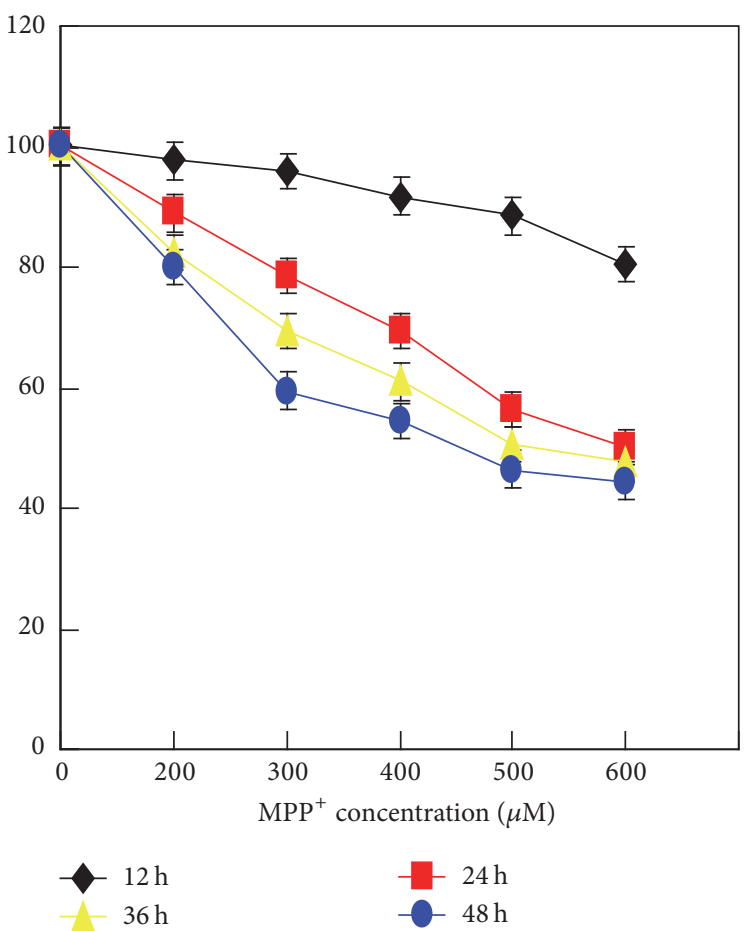

(b)

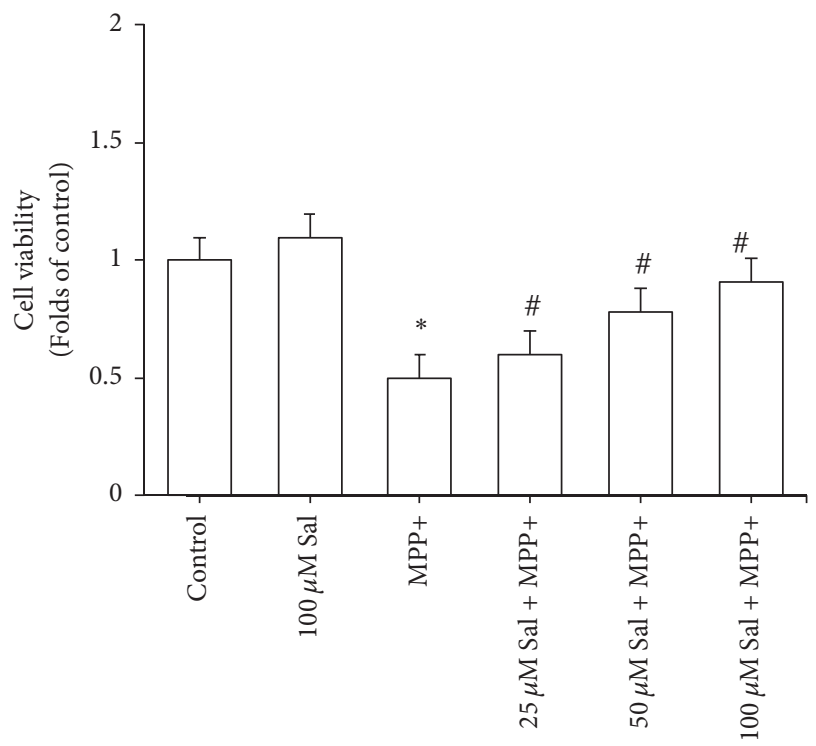

(c)

FIGURE 1: Effect of Sal on cell viability in MPP+-treated SH-SY5Y cells. SH-SY5Y cells were pretreated with $25-100 \mu \mathrm{M}$ Sal for $24 \mathrm{~h}$ and then exposed to $500 \mu \mathrm{M} \mathrm{MPP}+$ for an additional $24 \mathrm{~h}$. At the end, cell viability was determined by MTT assay. ${ }^{*} p<0.05$, compared with control. ${ }^{\#} p<0.05$, compared with MPP+ treated cells.

of the pathogenesis and treatment of PD [16-18]. The neurotoxin MPTP causes neurotoxicity through the active metabolite MPP+ (1-methyl-4-phenylpyridinium). MPP+ could be selectively taken up by dopaminergic neurons via the dopamine transporter of the plasma membrane [19]. $\mathrm{MPP}+$ results in neuronal loss in substantia nigra and striatal dopamine (DA) depletion, leading to PD-like behavioral impairments [20, 21]. Moreover, oxidative stress is involved in MPP+-associated PD-like neuronal injury [22, 23].
DJ-1 is a novel antioxidant protein and abnormal regulation of DJ-1 is closely related to the development of PD [24-27]. In the present study, we aimed to investigate whether the neuroprotective activities of Sal against PD involve the regulation of DJ-1, using SH-SY5Y cells, a clonal human neuroblastoma cell line. We found that Sal protects against MPP+-induced apoptotic cell death in SH-SY5Y cells through regulation of DJ-1-nuclear factor- (erythroid-derived 2-) like 2 (Nrf2) pathway. 


\section{Materials and Methods}

2.1. Chemicals and Materials. $\beta$-actin and Nrf2 antibodies were purchased from Santa Cruz Biotechnology Inc. (Santa Cruz). DJ-1, GCLc, SOD1, and SOD2 antibodies were obtained from Cell Signaling Technology (CST, USA). Hoechst 33258 and $\mathrm{MPP}^{+}$were obtained from Sigma (St. Louis, MO). Sal was obtained from the National Institute for the Control of Pharmaceutical and Biological Products, Xi'an, China.

2.2. Cell Culture and Transfection. SH-SY5Y cells were purchased from American Type Culture Collection (ATCC, USA) and cultured in Dulbecco's modified Eagle medium (Gibco, Gaithersburg, MD, USA) supplemented with $10 \%$ heat-inactivated horse serum (Gibco), 5\% heat-inactivated fetal calf serum (Gibco), $100 \mathrm{IU} / \mathrm{ml}$ penicillin, and $100 \mathrm{mg} / \mathrm{ml}$ streptomycin in a humidified incubator containing $5 \% \mathrm{CO}_{2}$ at $37^{\circ} \mathrm{C}$. SH-SY5Y cells were treated with $50 \mathrm{ng} / \mathrm{ml} 2.5 \mathrm{~S}$ nerve growth factor (Promega, Madison, WI, USA) for 9 days to induce differentiation. Cells were plated in 6-well plates and passaged at $60-70 \%$ confluence. In the experiments, cells were pretreated with $25-100 \mu \mathrm{M}$ Sal for $24 \mathrm{~h}$ and then exposed to $500 \mu \mathrm{M} \mathrm{MPP}+$ for an additional $24 \mathrm{~h}$. In some experiments, cells were transfected with siNrf2 or siDJ-1 (Santa Cruz Biotechnology) using lipofectamine 2000 transfection reagent 2-4 days before the treatment of Sal and MPP+.

2.3. Cell Viability. SH-SY5Y cells were seeded in 96-well plates at $1 \times 10^{4}$ cells per well. After the treatment with Sal and MPP+, cell viability was measured by the 3(4,5-dimethylthiazol-2-yl)-2,5-diphenyltetrazolium bromide (MTT; Sigma Aldrich) assay. Briefly, cells were incubated with $500 \mu \mathrm{g} / \mathrm{ml} \mathrm{MTT}$ at $37^{\circ} \mathrm{C}$ for $4 \mathrm{~h}$. After that, the medium was removed and $150 \mu$ l dimethyl sulfoxide (DMSO) was added and shaking was conducted for $10 \mathrm{~min}$. Absorbance was measured at $570 \mathrm{~nm}$ in a microplate reader (BioRad, USA) and the results were expressed as folds of control.

2.4. Determination of Cell Death. Cell death was evaluated using an FITC-labeled Annexin V and propidium iodide (PI) assay kit (Sigma). In brief, after the treatment, cells were harvested and centrifuged and then resuspended in binding buffer at a concentration of $1 \times 10^{6}$ cells $/ \mathrm{ml}$. Then, the mixture was added with $5 \mu \mathrm{l}$ of $20 \mu \mathrm{g} / \mathrm{ml}$ Annexin $\mathrm{V}$ and $50 \mu \mathrm{g} / \mathrm{ml}$ $\mathrm{PI}$ and incubated in a humidified incubator for $15 \mathrm{~min}$. After the binding, cell death was analyzed by a flow cytometer (BD Biosciences, CA, USA).

2.5. Evaluation of Cell Morphology. SH-SY5Y cells were plated on coverslips precoated with poly-L-lysine in 24-well plates and treated by Sal and MPP+ as mentioned above. After the treatment, cells were fixed with $4 \%$ paraformaldehyde for $30 \mathrm{~min}$, washed with PBS, and then incubated with Hoechst $33258(3 \mu \mathrm{g} / \mathrm{ml})$ for $30 \mathrm{~min}$ at room temperature in the dark. After rinsing with PBS, fluorescence was assessed using a fluorescence microscope (Olympus, Japan).

2.6. Reverse Transcriptase-Polymerase Chain Reaction Analysis (RT-PCR). mRNA was isolated from the cells using trizolreagent (Invitrogen, USA) and the quality of isolated RNA was checked by $1.2 \%$ formaldehyde. The RT-PCR reaction used a template cDNA followed by PCR amplification with Taq DNA polymerase in the same tube. PCR products were analyzed by $1.5 \%$ agarose gel electrophoresis, stained with ethidium bromide, and photographed under ultraviolet light.

2.7. Western Blot Analysis. Cells were lysed in lysis buffer [50 mM Tris-Cl (pH 8.0), $150 \mathrm{mM} \mathrm{NaCl}, 0.5 \mathrm{mM} \mathrm{MgCl}_{2}$, $10 \%$ glycerol, $1 \%$ Triton X-100, and $0.1 \%$ SDS] with protease inhibitor cocktail (Roche Diagnostics, Switzerland) on ice for $20 \mathrm{~min}$. The lysates were centrifuged for $20 \mathrm{~min}$ at $20,000 \mathrm{~g}$. Protein concentration was determined using BCA method (Thermo Fisher Scientific, USA) and lysates were mixed with loading buffer. The protein mixtures were separated by SDS-PAGE and transferred to PVDF membranes. The membranes were incubated with primary antibodies and then incubated with HRP-conjugated secondary antibody (Thermo Fisher Scientific, USA). Bands were visualized by chemiluminescence reaction using an ECL detection system (Thermo Fisher Scientific, USA), followed by capture using BioRad Imaging Systems (BIORAD, USA).

2.8. Evaluation of Oxidative Stress. For the determination of ROS, cells were incubated with $1 \mu \mathrm{M} 5$-(and-6)chloromethyl-2' $7^{\prime}$-dichlorodihydrofluorescein diacetate and acetyl ester (Thermo Fisher) prepared in Hank's Balanced Salt Solution for $20 \mathrm{~min}$ at $37^{\circ} \mathrm{C}$ and then washed for three times and scanned using a microplate fluorometer (Tecan) with $\mathrm{Ex}$ at $510 \mathrm{~nm} / \mathrm{Em}$ at $580 \mathrm{~nm}$ and $\mathrm{Ex}$ at $495 \mathrm{~nm} / \mathrm{Em}$ at $520 \mathrm{~nm}$, respectively. Glutathione was measured using a luminescence-based system (GSH Assay, Promega, Madison, WI, USA). Cells were washed with Hank's Balanced Salt Solution and lysed with lysis regents. The GSH level was expressed as in relative light units (RLU)/mg protein.

2.9. Statistical Analysis. All assays were carried out in three independent experiments and the results were expressed as the mean \pm SEM and analyzed by GraphPad Prism software. The statistical significance of differences among more than two groups was analyzed by one-way analysis of variance (ANOVA) followed by Dunnett's $t$-test for multiple comparisons. The data were deemed to be statistically significant when the $p$ value was less than 0.05 .

\section{Results}

3.1. Sal Protects against MPP+-Induced Cytotoxicity in SHSY5Y Cells. SH-SY5Y cells are usually used as a neuron model for studies of MPP+ neurotoxicity and PD [28]. In the present study, we evaluated the neuroprotective effect of Sal using SH-SY5Y cells. Cells were exposed to $0-600 \mu \mathrm{M}$ $\mathrm{MPP}+$ for $12-48 \mathrm{~h}$ and the results showed that MPP+ resulted in a significant decrease of cell viability in a concentration and time-dependent manner (Figure 1(b)). Cells were pretreated with $25-100 \mu \mathrm{M}$ Sal for $24 \mathrm{~h}$ and then exposed to $500 \mu \mathrm{M} \mathrm{MPP}+$ for an additional $24 \mathrm{~h}$. We showed that Sal concentration-dependently prevented $\mathrm{MPP}+$-induced decrease of cell viability (Figure 1(c)). Annexin V/PI staining is a common method for the detection of apoptotic cell. We found that Sal significantly decreased the number of Annexin V/PI-stained cells treated by MPP+ which was in a concentration-dependent manner (Figure 2(a)). Apoptotic 


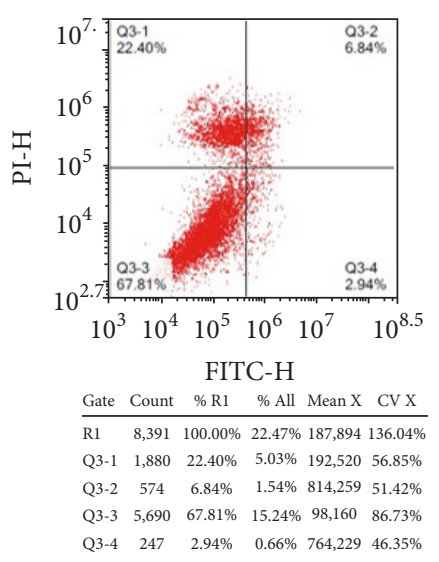

Control

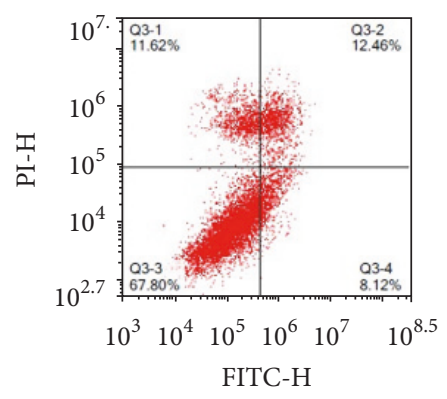

\begin{tabular}{lccccc} 
Gate & Count & $\%$ R1 & \% All & Mean X & CV X \\
\hline R1 & 8,349 & $100.00 \%$ & $23.42 \%$ & 319,493 & $127.69 \%$
\end{tabular} $\begin{array}{llllll}\text { Q3-1 } & 970 & 11.62 \% & 2.72 \% & 221,907 & 52.06 \%\end{array}$ Q3-2 $\quad 1,040 \quad 12.46 \% \quad 2.92 \% \quad 1,041,511 \quad 54.76 \%$ $\begin{array}{lllllll}\text { Q3-3 } & 5,661 & 67.80 \% & 15.88 \% & 146,938 & 71.87 \%\end{array}$ $\begin{array}{lllllll}\text { Q3-4 } & 678 & 8.12 \% & 1.90 \% & 792,345 & 49.40 \%\end{array}$ $25 \mu \mathrm{M} \mathrm{Sal}+\mathrm{MPP}^{+}$

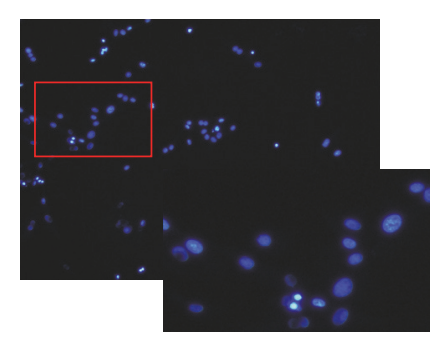

Control

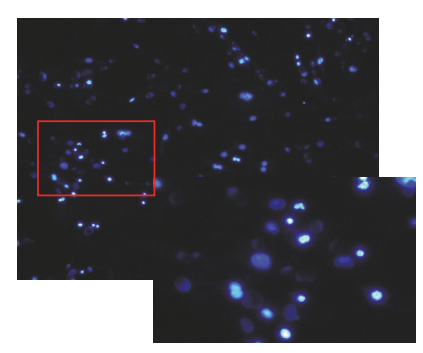

$25 \mu \mathrm{M} \mathrm{Sal}+\mathrm{MPP}^{+}$
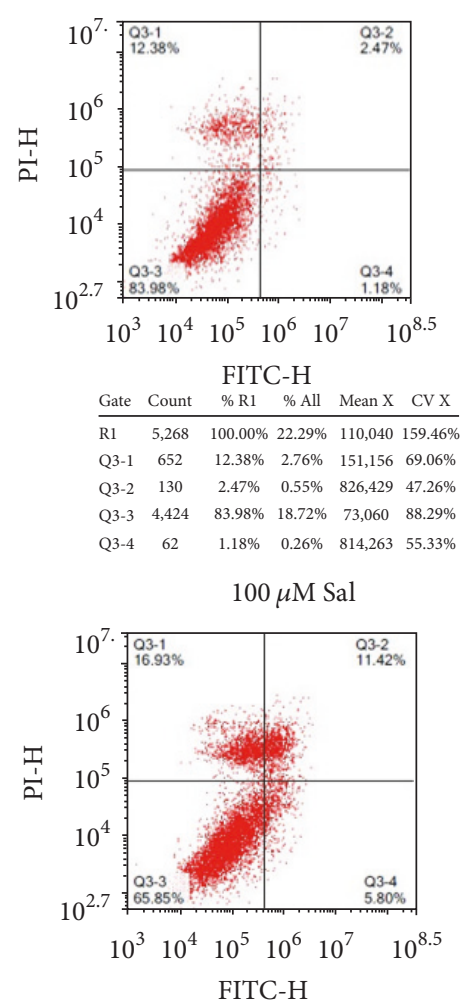

\begin{tabular}{lccccc} 
Gate & Count & $\%$ R1 & $\%$ All & Mean X & CV X \\
\hline R1 & 8,021 & $100.00 \%$ & $14.77 \%$ & 253,554 & $131.11 \%$
\end{tabular} $\begin{array}{llllll}\text { Q3-1 } & 1,358 & 16.93 \% & 2.50 \% & 213,072 & 54.61 \%\end{array}$ Q3-2 $\quad 916 \quad 11.42 \% \quad 1.69 \% \quad 858,310 \quad 51.52 \%$ Q3-3 $\quad 5,282 \quad 65.85 \% \quad 9.73 \% \quad 112,172 \quad 85.65 \%$ Q3-4 $\quad 465 \quad 5.80 \% \quad 0.86 \% \quad 786,439 \quad 47.73 \%$ $50 \mu \mathrm{M} \mathrm{Sal}+\mathrm{MPP}^{+}$

(a)

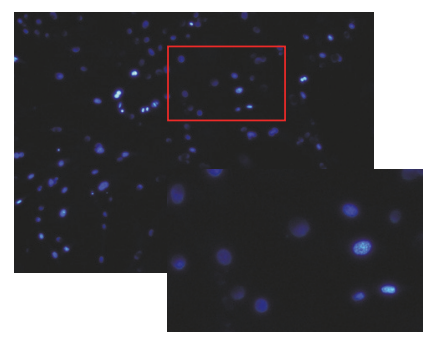

$100 \mu \mathrm{M} \mathrm{Sal}$

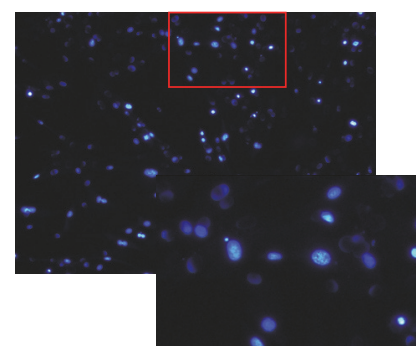

$50 \mu \mathrm{M} \mathrm{Sal}+\mathrm{MPP}^{+}$

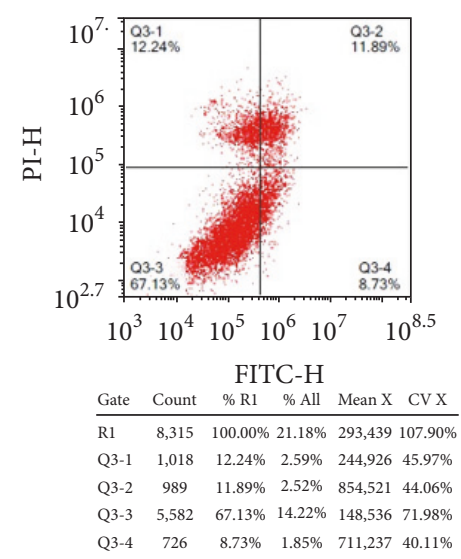

$\mathrm{MPP}^{+}$

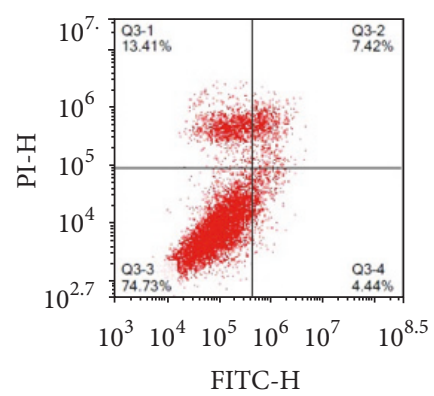

Gate Count \%R1 \%All Mean X CVX \begin{tabular}{lllllllllll}
\hline R1 & 8,370 & $100.00 \%$ & $20.04 \%$ & 214,521 & $149.05 \%$
\end{tabular} Q3-1 $\quad 1,122 \quad 13.41 \% \quad 2.69 \% \quad 185,112 \quad 59.46 \%$ $\begin{array}{lllllll}\text { Q3-2 } & 621 & 7.42 \% & 1.49 \% & 976,834 & 57.25 \%\end{array}$ $\begin{array}{lllllll}\text { Q3-3 } & 6,255 & 74.73 \% & 14.98 \% & 111,240 & 81.69 \%\end{array}$ Q3-4 $\quad 372 \quad 4.44 \% \quad 0.89 \% \quad 767,281 \quad 49.82 \%$ $100 \mu \mathrm{M} \mathrm{Sal}+\mathrm{MPP}^{+}$

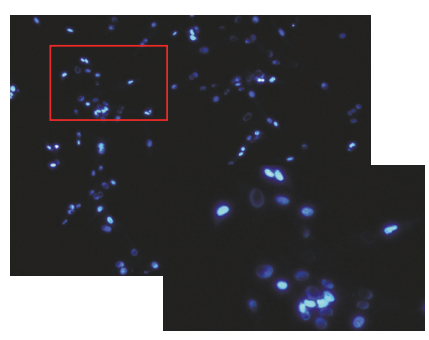

$\mathrm{MPP}^{+}$

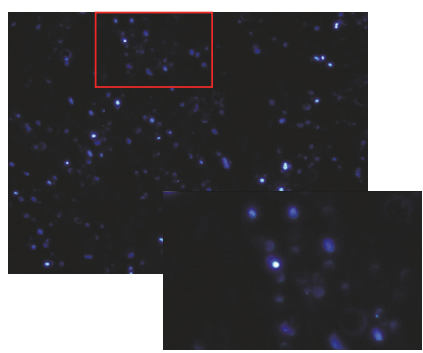

$100 \mu \mathrm{M} \mathrm{Sal}+\mathrm{MPP}^{+}$

(b)

FIgURE 2: Effect of Sal on cell death in MPP+-treated SH-SY5Y cells. SH-SY5Y cells were pretreated with $25-100 \mu \mathrm{M}$ Sal for $24 \mathrm{~h}$ and then exposed to $500 \mu \mathrm{M} \mathrm{MPP}+$ for an additional $24 \mathrm{~h}$. At the end, cell death was determined using Annexin V/PI assay kit and analyzed by flow cytometry (a). Cells were also stained with Hoechst to observe the morphological changes of nuclei (b). 

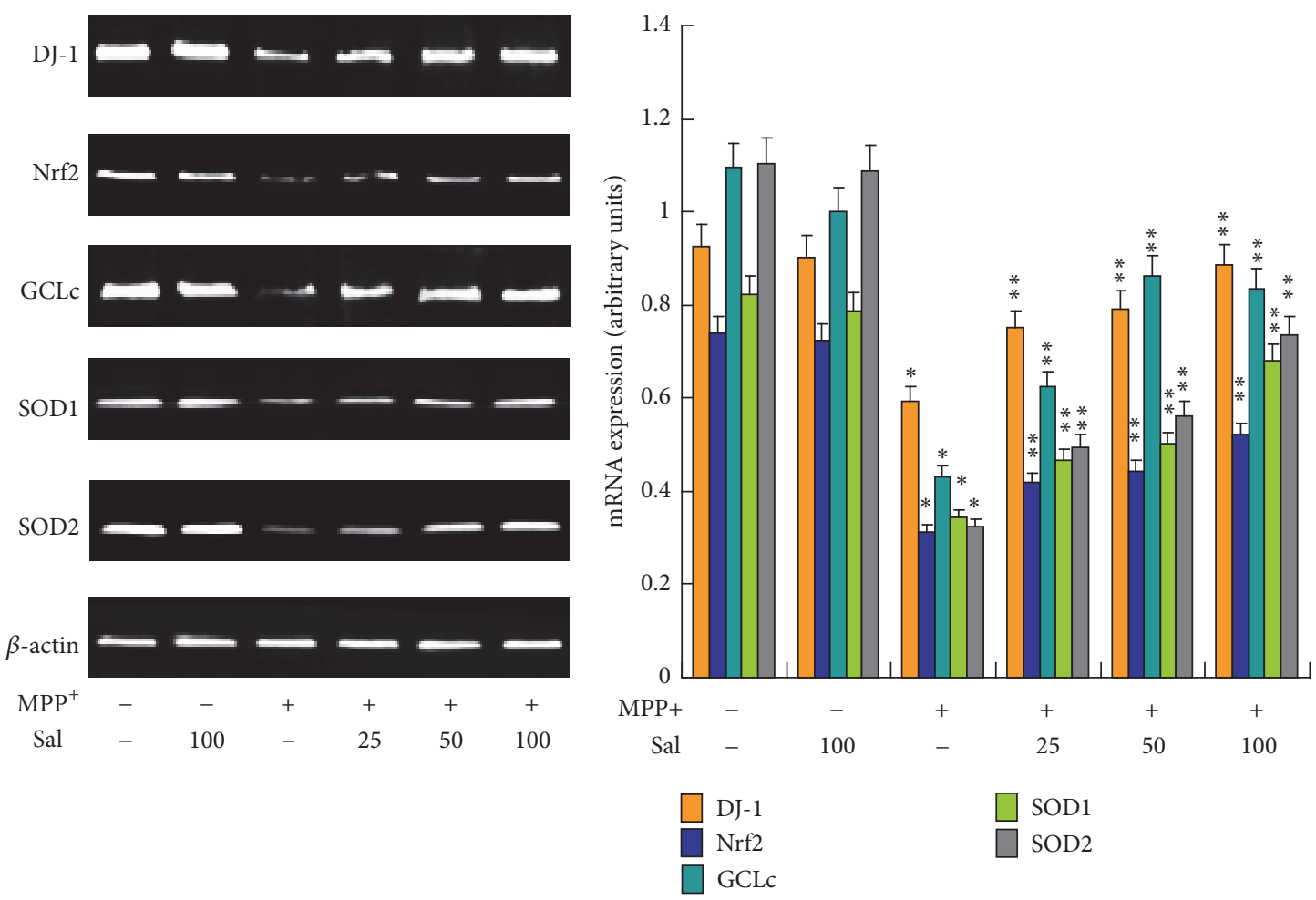

(a)

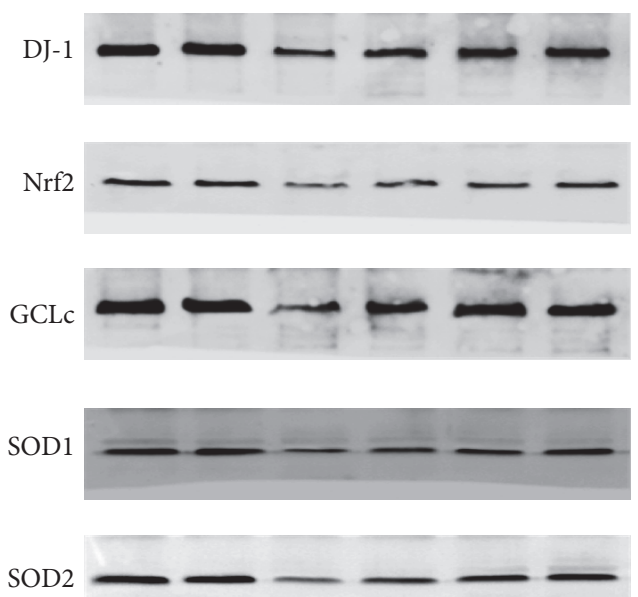

(c)

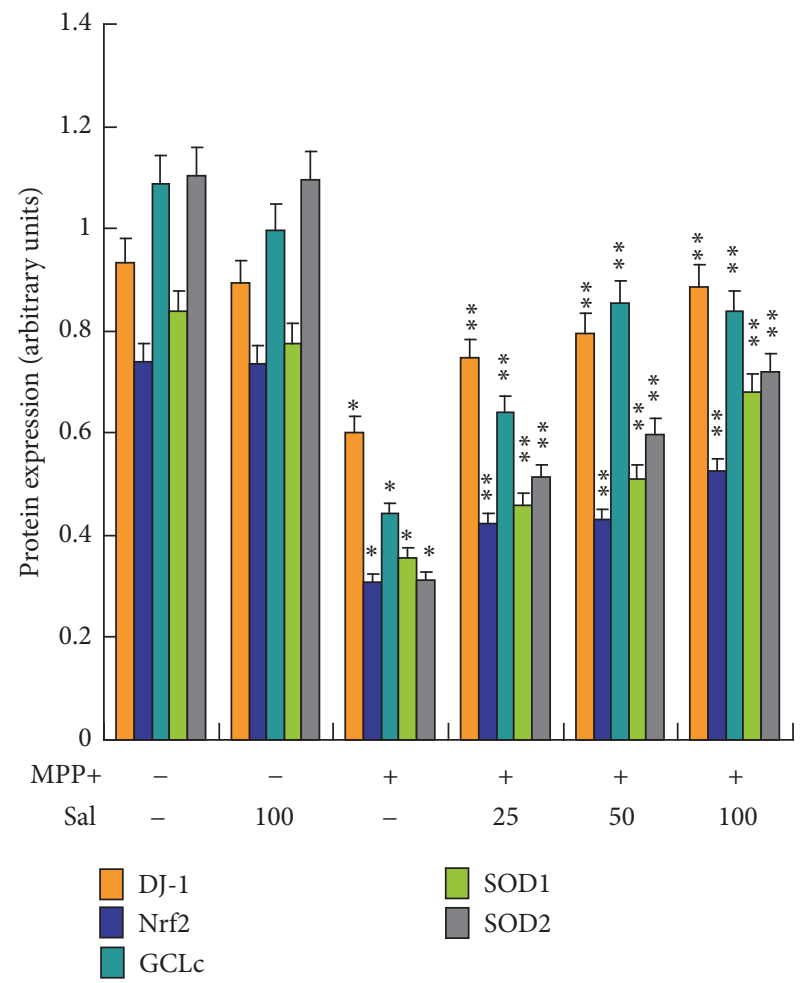

(d)

FIGURE 3: Effect of Sal on key antioxidant regulator expression in MPP+-treated SH-SY5Y cells. SH-SY5Y cells were pretreated with 25-100 $\mu \mathrm{M}$ Sal for $24 \mathrm{~h}$ and then exposed to $500 \mu \mathrm{M}$ MPP+ for an additional $24 \mathrm{~h}$. ((a) and (b)) mRNA expression of DJ-1, Nrf2, GCLc, SOD1, and SOD2 was determined and statistical analysis was showed. ((c) and (d)) Protein expression of DJ-1, Nrf2, GCLc, SOD1, and SOD2 was determined and statistical analysis was showed. ${ }^{*} p<0.05$, compared with control. ${ }^{* *} p<0.05$, compared with $\mathrm{MPP}^{+}$. 


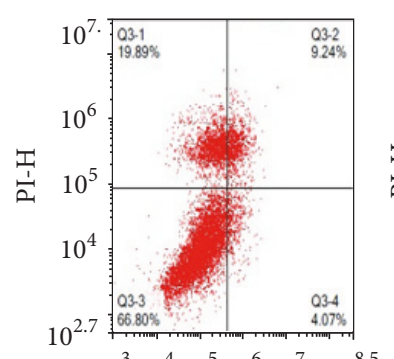

$10^{3} 10^{4} 10^{5} 10^{6} 10^{7} 10^{8.5}$ FITC-H Gate Count \% R1 \% All Mean X CVX R1 $\quad 8,919$ 100.00\% 33.13\% $230,837 \quad 116.79 \%$ Q3-1 1,774 19.89\% 6.59\% 223,462 $47.82 \%$ Q3-2 $824 \quad 9.24 \% \quad 3.06 \%$ 771,015 53.02\% $\begin{array}{lllll}\text { Q3-3 5,958 } & 66.80 & 22.13 \% & 127,655 & 75.36 \%\end{array}$ $\begin{array}{llllll}\text { Q3-4 } & 363 & 4.07 \% & 1.35 \% & 734,238 & 44.91 \%\end{array}$

Control +

Scramble siRNA

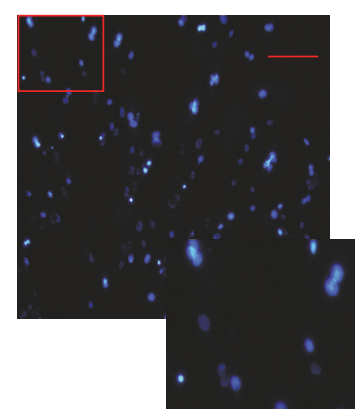

Control + Scramble siRNA

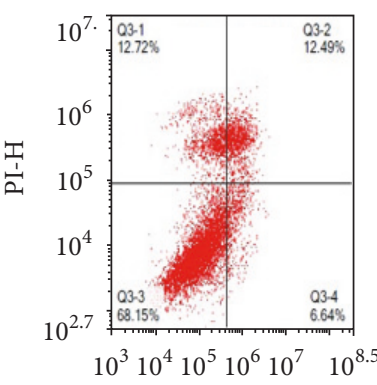

FITC-H

Gate Count \% R1 \% All Mean X CV X

R1 $\quad 7,957100.00 \% 16.29 \% 284,051126.95 \%$ Q3-1 1,012 12.72\% 2.07\% 217,795 54.86\% Q3-2 $994 \quad 12.49 \% \quad 2.04 \% 913,021 \quad 48.32 \%$ Q3-3 5,423 68.15\% 11.10\% 129,922 76.85\% Q3-4 $528 \quad 6.64 \% \quad 1.08 \% 809,99753.82 \%$

$\mathrm{MPP}^{+}$

+ Scramble siRNA

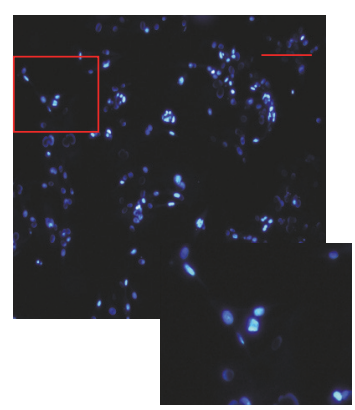

$\mathrm{MPP}^{+}$

+ Scramble siRNA

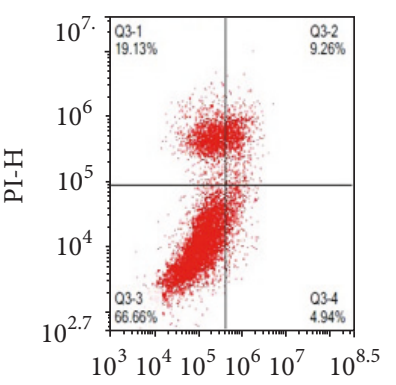

FITC-H

Gate Count \%R1 \% All Mean X CV X R1 $\quad 8,959 \quad 100.00 \% 34.18 \% 253,311121.93 \%$ Q3-1 $\quad 1,714 \quad 19.13 \% \quad 6.54 \% 215,740 \quad 49.69 \%$ Q3-2 $\quad 830 \quad 9.26 \% \quad 3.17 \% \quad 882,734 \quad 55.85 \%$ Q3-3 5,972 66.66\% 22.78\% 139,683 71.37\% Q3-4 $\quad 443 \quad 4.94 \% \quad 1.69 \% 751,18947.34 \%$

$100 \mu \mathrm{M} \mathrm{Sal}+\mathrm{MPP}^{+}$

+ Scramble siRNA

(a)

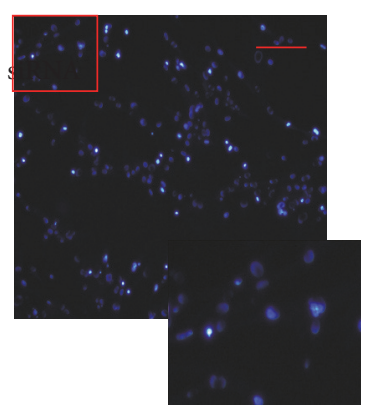

$100 \mu \mathrm{M} \mathrm{Sal}+\mathrm{MPP}^{+}$ + Scramble siRNA

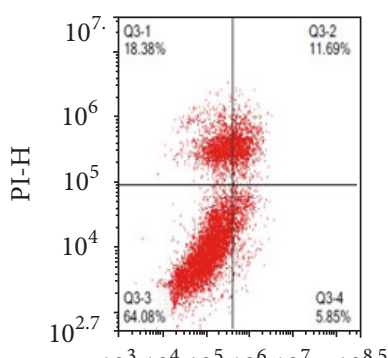

$10^{3} 10^{4} 10^{5} 10^{6} 10^{7} \quad 10^{8.5}$ FITC-H Gate Count \% R1 \% All Mean X CVX R1 $\quad 8,495100.00 \% 21.05 \% 273,442119.57 \%$ Q3-1 1 1,561 $18.38 \% \quad 3.87 \% \quad 232,763 \quad 49.62 \%$ Q3-2 $993 \quad 11.69 \% \quad 2.46 \% \quad 850,894 \quad 49.28 \%$ Q3-3 5,444 64.08\% $13.49 \% 132,697 \quad 76.22 \%$ Q3-4 $\quad 497 \quad 5.85 \% \quad 1.23 \% \quad 789,14651.96 \%$

$100 \mu \mathrm{M} \mathrm{Sal}+\mathrm{MPP}^{+}$ $+\operatorname{siNrf2}$

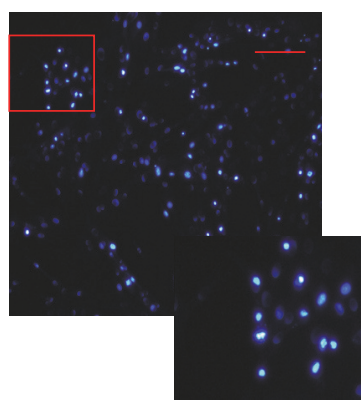

$100 \mu \mathrm{M} \mathrm{Sal}+\mathrm{MPP}^{+}$ + siNrf2

(b)

FIGURE 4: Role of Nrf2 in Sal-induced effects on cell death in MPP+-treated SH-SY5Y cells. SH-SY5Y cells were transfected with siNrf2, pretreated with 25-100 $\mu \mathrm{M}$ Sal for $24 \mathrm{~h}$, and then exposed to $500 \mu \mathrm{M}$ MPP+ for an additional $24 \mathrm{~h}$. At the end, cell death was determined using Annexin V/PI assay kit and analyzed by flow cytometry (a). Cells were also stained with Hoechst to observe the morphological changes of nuclei (b).

cell could also be morphologically evaluated by Hoechst staining. In Hoechst staining, apoptotic cells are characterized by reduced nuclear size, chromatin condensation, intense fluorescence, and nuclear fragmentation. We showed that Sal notably inhibited MPP+-induced increase of chromatin condensation, intense fluorescence, and nuclear fragmentation in SH-SY5Y cells (Figure 2(b)). These results indicated that Sal protected against MPP+-induced cytotoxicity in SH-SY5Y cells.

\subsection{Sal Protects against MPP+-Induced Changes of Antioxi-} dant Protein Expression in SH-SY5Y Cells. To further examine the mechanism of Sal-exhibited neuroprotective effects, we examined the effect of Sal on the expression of key antioxidant proteins, including DJ-1, Nrf2, glutamate-cysteine ligase catalytic subunit (GCLc), superoxide dismutase 1 (SOD1), and SOD2. The results showed that $\mathrm{MPP}+$ induced a significant decrease of the mRNA (Figures 3(a) and 3(b)) and protein (Figures 3(c) and 3(d)) expression of DJ-1, Nrf2, GCLc, SOD1, and SOD2. The treatment of Sal significantly prevented MPP+-induced decrease of the mRNA (Figures 3(a) and 3(b)) and protein (Figures 3(c) and 3(d)) expression of DJ-1, Nrf2, GCLc, SOD1, and SOD2 in SH-SY5Y cells. The results indicated that $\mathrm{Sal}$ exhibited protective effects against $\mathrm{MPP}+$-induced imbalance of redox state through regulation of key antioxidant proteins.

3.3. Upregulation of Nrf2 Is Involved in the Neuroprotective Effects of Sal against MPP+ Cytotoxicity. To examine whether regulation of Nrf2 was involved in the neuroprotective effects of Sal against MPP+ cytotoxicity, SH-SY5Y cells were transfected with siNrf2. We showed that silencing of Nrf2 significantly suppressed the decrease of Annexin V/PI-stained cells induced by Sal in MPP+-treated SH-SY5Y cells (Figure 4(a)). Sal-induced decrease of chromatin condensation, intense fluorescence, and nuclear fragmentation in MPP+-treated cells were inhibited by siNrf2 (Figure 4(b)). Moreover, silencing of Nrf2 significantly inhibited Sal-induced increase in mRNA (Figures 5(a) and 5(b)) and protein (Figures 5(c) and 5(d)) expression of Nrf2, GCLc, SOD1, and SOD2 in MPP+-treated 


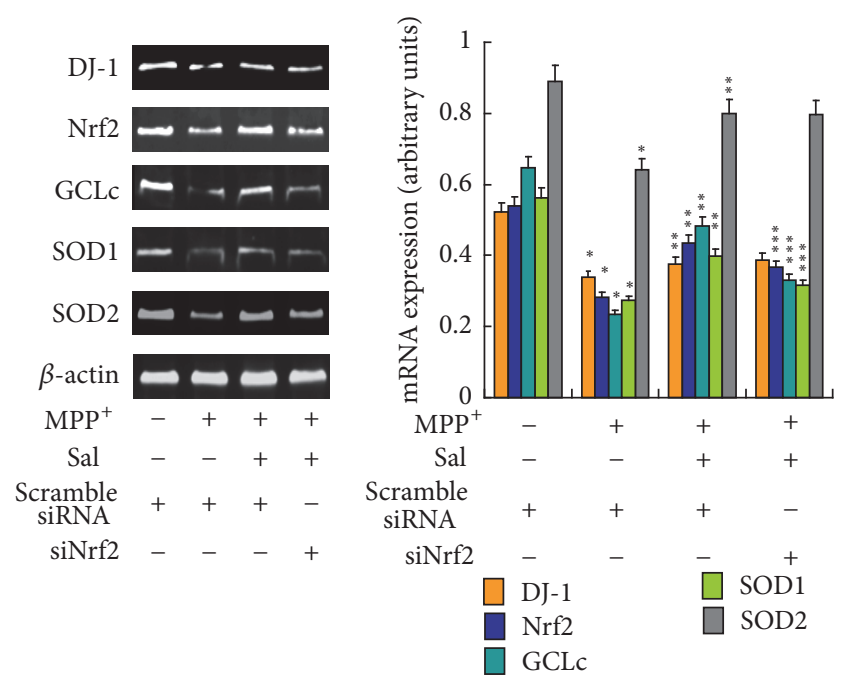

(a) (b)

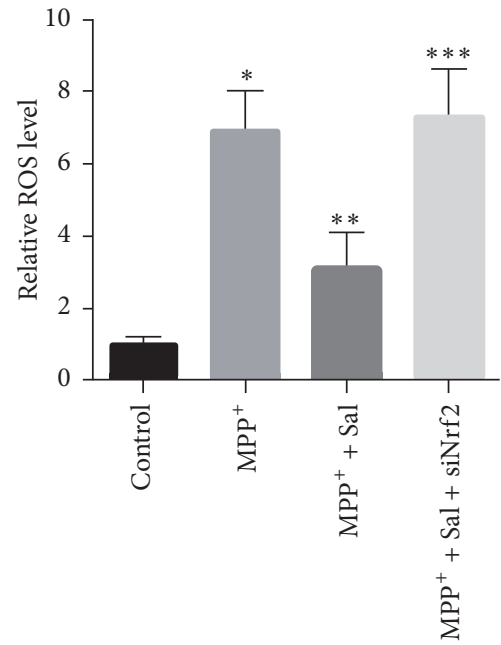

(e)

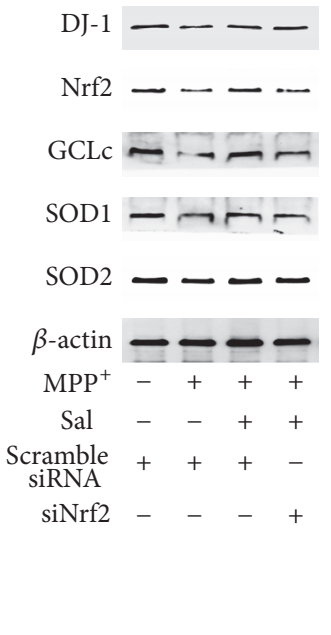

(c)

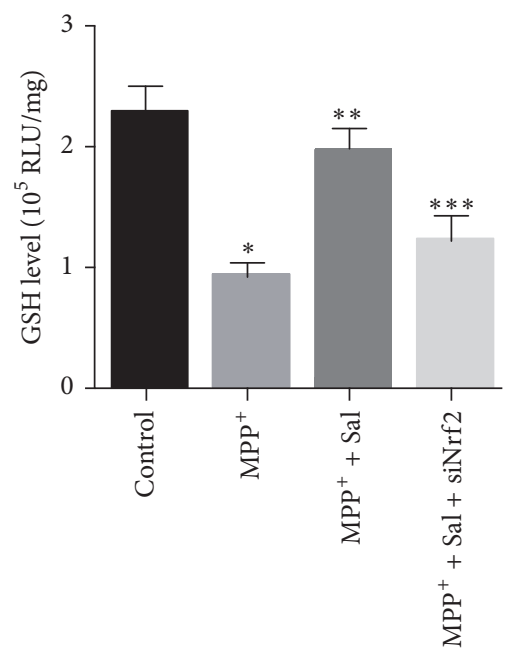

(f)

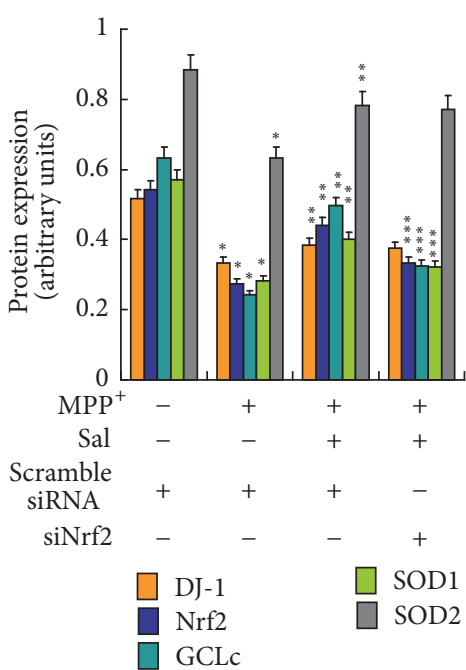

(d)

FIgURE 5: Role of Nrf2 in Sal-induced effects key antioxidant regulator expression in MPP+-treated SH-SY5Y cells. SH-SY5Y cells were transfected with siNrf2, pretreated with $25-100 \mu \mathrm{M}$ Sal for $24 \mathrm{~h}$, and then exposed to $500 \mu \mathrm{M} \mathrm{MPP}+$ for an additional $24 \mathrm{~h}$. ((a) and (b)) mRNA expression of DJ-1, Nrf2, GCLc, SOD1, and SOD2 was determined and statistical analysis was showed. ((c) and (d)) Protein expression of DJ-1, Nrf2, GCLc, SOD1, and SOD2 was determined and statistical analysis was showed. (e) ROS level was determined using DCFH-DA staining. (f) GSH level was determined by an assay kit. ${ }^{*} p<0.05$, compared with control. ${ }^{* *} p<0.05$, compared with $\mathrm{MPP}^{+}$. ${ }^{* * *} p<0.05$, compared with Sal.

SH-SY5Y cells. However, Nrf2 silence did not significantly affect Sal-exhibited effects on DJ-1 expression (Figures 5(a), 5(b), 5(c), and 5(d)). Moreover, Sal inhibited MPP+-induced increase of reactive oxygen species (ROS) (Figure 5(e)) and decrease of glutathione (GSH) level (Figure 5(f)). Silencing of Nrf2 significantly inhibited Sal-induced decrease ROS level and increase of GSH level in MPP+-treated cells (Figures 5(e) and 5(f)). The results indicated that Nrf2-regulated antioxidant enzymes were involved in the neuroprotective effects of Sal against MPP+ toxicity.

3.4. Upregulation of DJ-1 Is Involved in the Neuroprotective Effects of Sal against MPP+ Cytotoxicity. SH-SY5Y cells were further transfected with siDJ-1 to examine whether regulation of DJ-1 was involved in the neuroprotective effects of Sal against MPP+ cytotoxicity. The results showed that silencing of DJ-1 significantly suppressed the decrease of Annexin $\mathrm{V} / \mathrm{PI}$-stained cells induced by Sal in MPP+-treated $\mathrm{SH}$ SY5Y cells (Figure 6(a)). Moreover, Sal-induced decrease of chromatin condensation, intense fluorescence, and nuclear fragmentation in MPP+-treated cells were inhibited by siDJ1 (Figure 6(b)). Furthermore, silencing of DJ-1 significantly inhibited Sal-induced increase in mRNA (Figures 7 (a) and 7(b)) and protein (Figures 7(c) and 7(d)) expression of DJ1, Nrf2, GCLc, SOD1, and SOD2 in MPP+-treated SH-SY5Y cells. Moreover, silencing of DJ-1 significantly inhibited Salinduced decrease of ROS level and increase of GSH level in MPP+-treated cells (Figures 7(e) and 7(f)). The results 


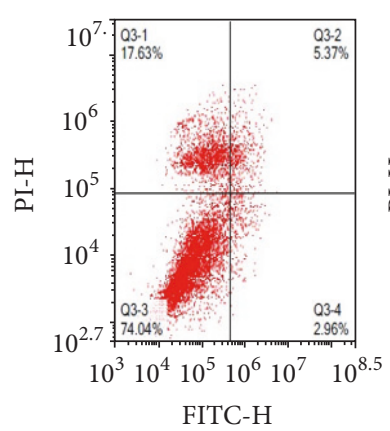

Gate Count \%R1 \%All Mean X CVX

R1 8,019 100.00\% $17.48 \% 160,929178.02 \%$ $\begin{array}{lllllll}\text { Q3-1 } & 1,414 & 17.63 \% & 3.08 \% & 160,520 & 68.29 \%\end{array}$ Q3-2 $\quad 431 \quad 5.37 \% \quad 0.94 \% \quad 933,030 \quad 61.19 \%$ Q3-3 5,937 74.04\% $12.94 \% \quad 77,022 \quad 98.88 \%$ $\begin{array}{llllll}\text { Q3-4 } & 237 & 2.96 \% & 0.52 \% & 861,162 & 54.29 \%\end{array}$ Control +

Scramble siRNA

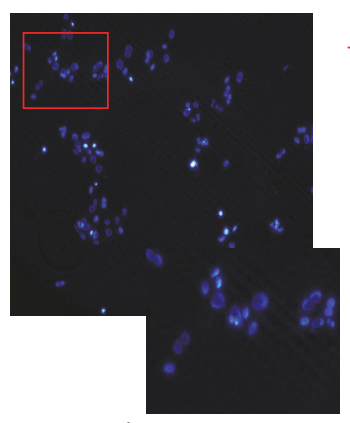

Control +

Scramble siRNA
Gate Count \%R1 \%All Mean X CVX

R1 $\quad 8,074 \quad 100.00 \% 19.10 \% 261,756128.15 \%$ $\begin{array}{llllll}\text { Q3-1 } & 868 & 10.75 \% & 2.05 \% & 218,820 & 53.09 \%\end{array}$ Q3-2 $\quad 718 \quad 8.89 \% \quad 1.70 \% \quad 914,887 \quad 53.67 \%$ Q3-3 5,893 72.99\% $13.94 \% \quad 135,297 \quad 75.99 \%$ $\begin{array}{llllll}\text { Q3-4 } & 595 & 7.37 \% & 1.41 \% & 788,725 & 50.46 \%\end{array}$ $\mathrm{MPP}^{+}$

+ Scramble siRNA
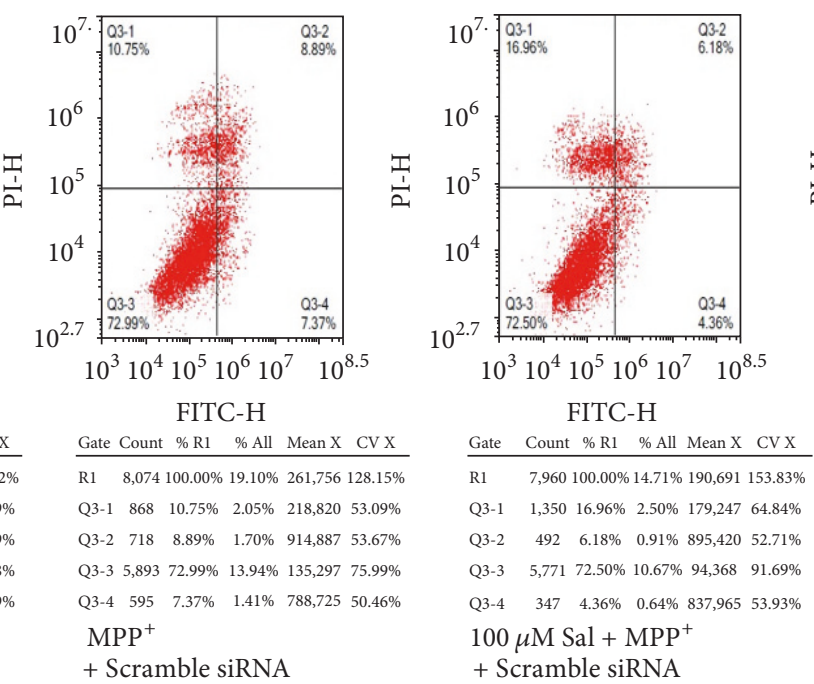

(a)

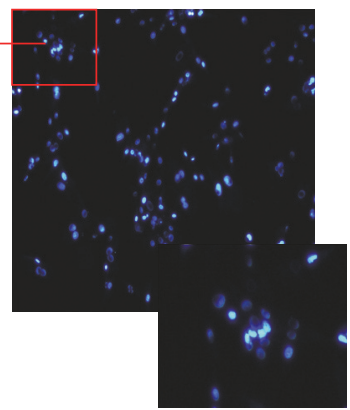

$\mathrm{MPP}^{+}$

+ Scramble siRNA

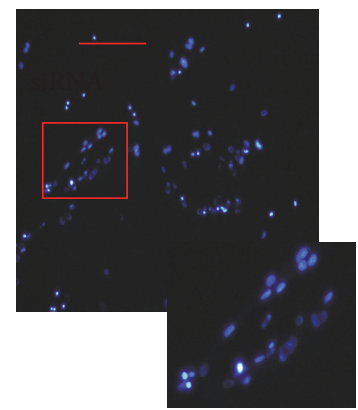

$100 \mu \mathrm{M} \mathrm{Sal}+\mathrm{MPP}^{+}$ + Scramble siRNA

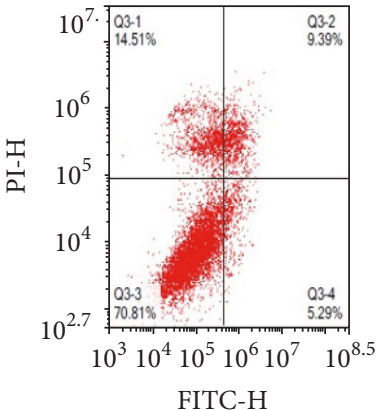

Gate Count \%R1 \%All Mean X CVX R1 $\quad 8,065100.00 \% 17.09 \% 240,980137.39 \%$ Q3-1 $\quad 1,170 \quad 14.51 \% \quad 2.48 \% \quad 205,019 \quad 59.57 \%$ Q3-2 $757 \quad 9.39 \% \quad 1.60 \% \quad 934,758 \quad 54.18 \%$ Q3-3 5,711 70.81\% 12.10\% 117,314 81.21\% Q3-4 $\quad 427 \quad 5.29 \% \quad 0.90 \% \quad 763,559 \quad 45.27 \%$ $100 \mu \mathrm{M} \mathrm{Sal}+\mathrm{MPP}^{+}$ + siDJ-1

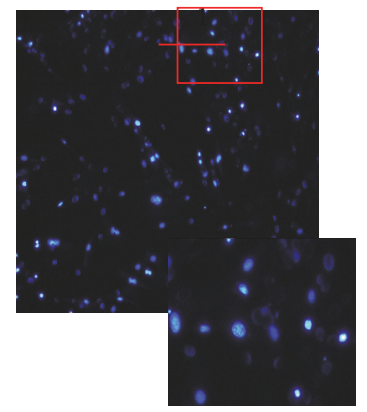

$100 \mu \mathrm{M} \mathrm{Sal}+\mathrm{MPP}^{+}$ + siDJ-1

(b)

FiguRE 6: Role of Nrf2 in Sal-induced effects on cell death in MPP+-treated SH-SY5Y cells. SH-SY5Y cells were transfected with siDJ-1, pretreated with $25-100 \mu \mathrm{M}$ Sal for $24 \mathrm{~h}$, and then exposed to $500 \mu \mathrm{M} \mathrm{MPP}+$ for an additional $24 \mathrm{~h}$. At the end, cell death was determined using Annexin V/PI assay kit and analyzed by flow cytometry (a). Cells were also stained with Hoechst to observe the morphological changes of nuclei (b).

indicated that DJ-1 was an upstream regulator of Nrf2antioxidant enzymes, which were involved in the neuroprotective effects of Sal against MPP+ toxicity.

\section{Discussion}

Our previous studies have found that Sal exhibited neuroprotective effects against MPP+ toxicity in vitro and in vivo $[14,15,29]$. However, the molecular mechanism underlying this beneficial effect is far from being completely understood. We explored the antioxidant mechanism of Sal-possessed neuroprotective effects in SH-SY5Y cells.

Increase of ROS generation and oxidative stress is considered to be a common pathway in the development of PD and its associated diseases [30-32]. It is well known that Nrf2 is central regulator of redox status in various biological processes. Nrf2 can bind with antioxidant response element, controlling the transcription of a battery antioxidant enzymes, including GCL and SOD [33]. SOD functions to catalyze the transition of $\mathrm{O}^{2-}$ to oxygen and $\mathrm{H}_{2} \mathrm{O}_{2}$. SOD1 (cytoplasmic copper and zinc SOD, Cu/ZnSOD) and SOD2 (mitochondrial manganese SOD, MnSOD) are the main types of SOD in organisms. GCLc is the catalytic subunit of GCL, which is the rate-limiting enzyme responsible for catalyzing de novo synthesis of glutathione (GSH) from the precursor amino acids cysteine, glutamate, and glycine [34]. GSH is the most important hydrophilic antioxidant and plays a critical role in various cellular processes through direct detoxification or acting as a cofactor. Abnormal expression of Nrf2, GCLc, SOD1, and SOD2 has been reported to be associated with PD and other neurodegenerative diseases [35-40]. In the present study, we tested the possible role of Nrf2 and related antioxidant enzymes in the protective effects of Sal. We found that Sal significantly prevented MPP+induced decrease of the mRNA and protein expression of Nrf2, GCLc, SOD1, and SOD2 in SH-SY5Y cells. Moreover, silencing of Nrf2 significantly inhibited Sal-induced increase in mRNA and protein expression of GCLc, SOD1, and SOD2 in MPP+-treated SH-SY5Y cells. But Nrf2 silence did not significantly affect Sal-exhibited impacts on DJ-1 expression, indicating that DJ-1 was not a downstream regulator of 


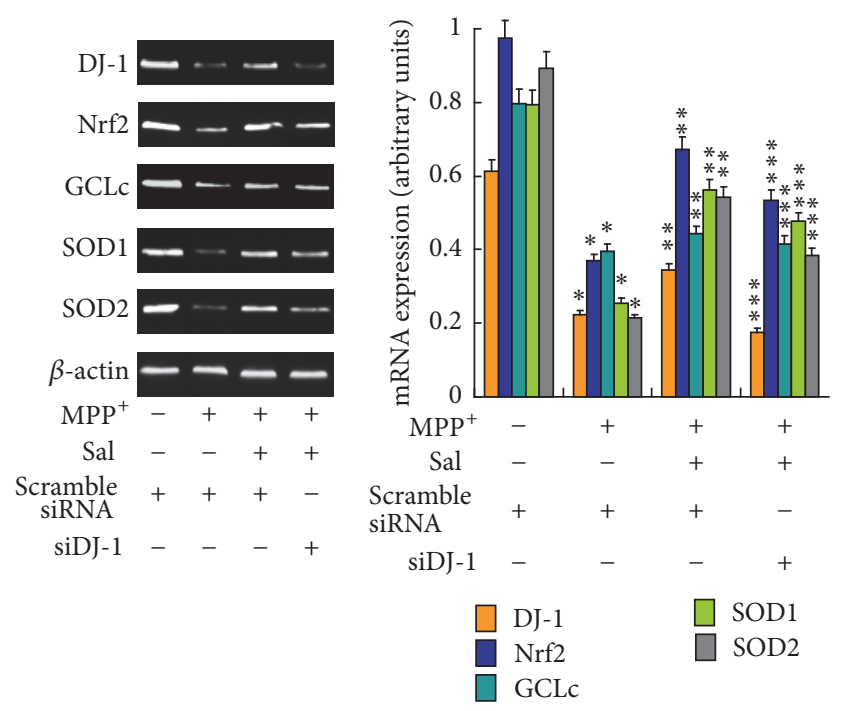

(a) (b)

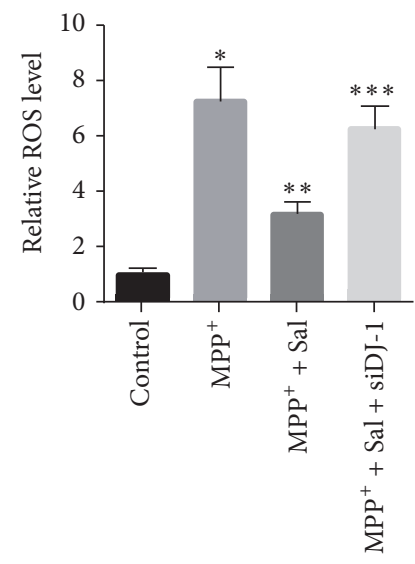

(e)

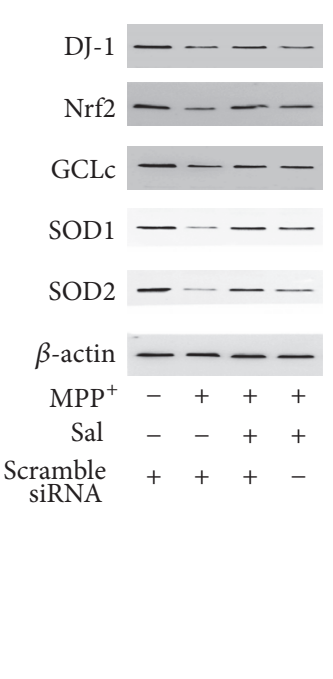

(c)

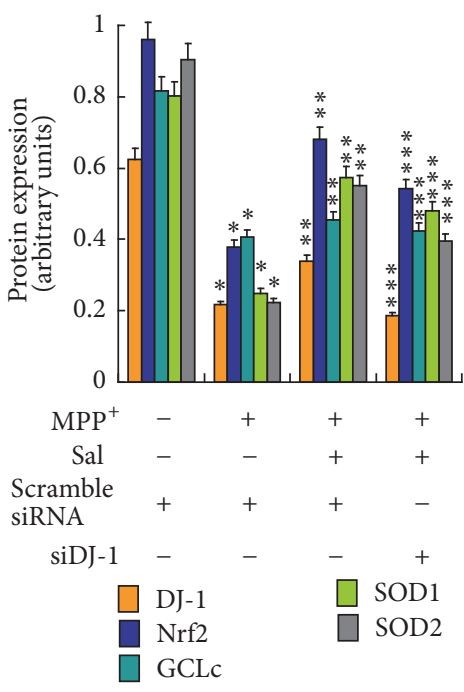

(d)

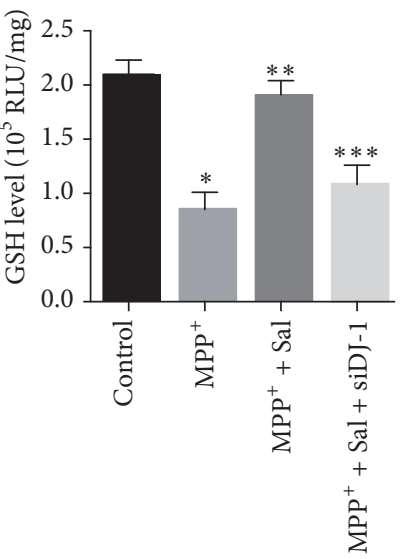

(f)

FIGURE 7: Role of Nrf2 in Sal-induced effects on key antioxidant regulator expression in MPP+-treated SH-SY5Y cells. H-SY5Y cells were transfected with siDJ-1, pretreated with 25-100 $\mu \mathrm{M}$ Sal for $24 \mathrm{~h}$, and then exposed to $500 \mu \mathrm{M} \mathrm{MPP}+$ for an additional $24 \mathrm{~h}$. ((a) and (b)) mRNA expression of DJ-1, Nrf2, GCLc, SOD1, and SOD2 was determined and statistical analysis was showed. ((c) and (d)) Protein expression of DJ-1, Nrf2, GCLc, SOD1, and SOD2 was determined and statistical analysis was showed. (e) ROS level was determined using DCFH-DA staining. (f) GSH level was determined by an assay kit. ${ }^{*} p<0.05$, compared with control. ${ }^{* *} p<0.05$, compared with $\mathrm{MPP}^{+}$. ${ }^{* * *} p<0.05$, compared with Sal.

Nrf2 signaling. Silencing of Nrf2 significantly suppressed the decrease of apoptosis induced by Sal in MPP+-treated SH-SY5Y cells. The results demonstrated that Nrf2-regulated antioxidant enzymes were involved in the neuroprotective effects of Sal.

DJ-1 is a novel antioxidant regulator that could protect cells from oxidative stress and induce Nrf2 expression [41]. Recent evidence has also suggested that abnormal function of DJ-1 plays a role in the pathogenesis of PD [42-44]. In this study, we also examined the role of DJ-1 in neuroprotective effects of Sal. We found that Sal significantly prevented MPP+-induced decrease of the mRNA and protein expression of DJ-1 in SH-SY5Y cells. Moreover, silencing of DJ-1 significantly inhibited Sal-induced increase in mRNA and protein expression of Nrf2, GCLc, SOD1, and SOD2 in
MPP+-treated SH-SY5Y cells. These results indicated that DJ1 was an upstream regulator of $\mathrm{Nrf} 2$ in neuroprotective effects of Sal. Furthermore, silencing of DJ-1 significantly suppressed the decrease of apoptosis induced by Sal in MPP+-treated SHSY5Y cells. The results demonstrated that DJ-1-regulated Nrf2 antioxidant pathway was involved in the neuroprotective effects of Sal.

In conclusion, we found that Sal prevented MPP+induced neurotoxicity through upregulation of DJ-1-Nrf2antioxidant pathway. Further studies are needed to investigate whether DJ-1 exhibits a transcriptional regulation of Nrf2 and those antioxidant enzymes or affects Nrf2-antioxidant enzymes through indirect regulation. Overall, our findings provide novel insights into the neuroprotective effects of Sal against $\mathrm{PD}$ and associated neurodegenerative diseases. 


\section{Conflicts of Interest}

The authors declare that there are no conflicts of interest.

\section{Acknowledgments}

This work was supported by grants from the Natural Science Foundation of China (Project no. 81173590).

\section{References}

[1] L. M. de Lau and M. M. Breteler, "Epidemiology of Parkinson's disease," The Lancet Neurology, vol. 5, no. 6, pp. 525-535, 2006.

[2] A. Navarro, A. Boveris, M. J. Bandez et al., "Human brain cortex: mitochondrial oxidative damage and adaptive response in Parkinson disease and in dementia with Lewy bodies," Free Radical Biology \& Medicine, vol. 46, pp. 1574-1580, 2009.

[3] M. Nagao and H. Hayashi, "Mixed lineage kinase 2 and hippocalcin are localized in Lewy bodies of Parkinson's disease," Journal of the Neurological Sciences, vol. 281, no. 1-2, pp. 51-54, 2009.

[4] A. J. Hughes, S. E. Daniel, Y. Ben-Shlomo, and A. J. Lees, “The accuracy of diagnosis of parkinsonian syndromes in a specialist movement disorder service," Brain, vol. 125, no. 4, pp. 861-870, 2002.

[5] G. J. McBean, M. G. López, and F. K. Wallner, "Redox-based therapeutics in neurodegenerative disease," British Journal of Pharmacology, vol. 174, no. 12, pp. 1750-1770, 2017.

[6] S. Singh, T. Das, A. Ravindran et al., "Involvement of nitric oxide in neurodegeneration: A study on the experimental models of Parkinson's disease," Redox Report, vol. 10, no. 2, pp. 103-109, 2005.

[7] W. Meissner, M. P. Hill, F. Tison, C. E. Gross, and E. Bezard, "Neuroprotective strategies for Parkinson's disease: Conceptual limits of animal models and clinical trials," Trends in Pharmacological Sciences, vol. 25, no. 5, pp. 249-253, 2004.

[8] T. Foltynie and J. Kahan, "Parkinson's disease: An update on pathogenesis and treatment," Journal of Neurology, vol. 260, no. 5, pp. 1433-1440, 2013.

[9] A. M. Díaz Lanza, M. J. Abad Martínez, L. Fernández Matellano et al., "Lignan and phenylpropanoid glycosides from Phillyrea latifolia and their in vitro anti-inflammatory activity," Planta Medica, vol. 67, no. 3, pp. 219-223, 2001.

[10] G. S. Kelly, "Rhodiola rosea: a possible plant adaptogen," Alternative Medicine Review, vol. 6, no. 3, pp. 293-302, 2001.

[11] A. Kucinskaite, V. Briedis, and A. Savickas, "Experimental analysis of therapeutic properties of Rhodiola rosea L. and its possible application in medicine," Medicina, vol. 40, no. 7, pp. 614-619, 2004

[12] Q.-S. Sheng, Z.-J. Wang, J. Zhang, and Y.-G. Zhang, "Salidroside promotes peripheral nerve regeneration following crush injury to the sciatic nerve in rats," NeuroReport, vol. 24, no. 5, pp. 217223,2013

[13] D. Yin, W. Yao, S. Chen, R. Hu, and X. Gao, "Salidroside, the main active compound of rhodiola plants, inhibits high glucoseinduced mesangial cell proliferation," Planta Medica, vol. 75, no. 11, pp. 1191-1195, 2009.

[14] X. Li, X. Ye, X. Li et al., "Salidroside protects against MPP+induced apoptosis in PC12 cells by inhibiting the NO pathway," Brain Research, vol. 1382, pp. 9-18, 2011.
[15] S. Wang, H. He, L. Chen, W. Zhang, X. Zhang, and J. Chen, "Protective effects of salidroside in the MPTP/MPP ${ }^{+}$-induced model of parkinson's disease through ros-no-related mitochondrion pathway," Molecular Neurobiology, 2014.

[16] F. Yue, S. Zeng, R. Tang, G. Tao, and P. Chan, "MPTP Induces Systemic Parkinsonism in Middle-Aged Cynomolgus Monkeys: Clinical Evolution and Outcomes," Neuroscience Bulletin, vol. 33, no. 1, pp. 17-27, 2017.

[17] X. Niu, H. Huang, J. Zhang et al., "Deletion of autophagy-related gene 7 in dopaminergic neurons prevents their loss induced by MPTP," Neuroscience, vol. 339, pp. 22-31, 2016.

[18] M. S. Nielsen, A. N. Glud, A. Møller et al., "Continuous MPTP intoxication in the göttingen minipig results in chronic parkinsonian deficits," Acta Neurobiologiae Experimentalis, vol. 76, no. 3, pp. 199-211, 2016.

[19] K. Chiba, A. Trevor, and N. Castagnoli Jr., "Metabolism of the neurotoxic tertiary amine, MPTP, by brain monoamine oxidase," Biochemical and Biophysical Research Communications, vol. 120, no. 2, pp. 574-578, 1984.

[20] C. S. Lee, J. H. Han, Y. Y. Jang, J. H. Song, and E. S. Han, "Differential effect of catecholamines and MPP+ on membrane permeability in brain mitochondria and cell viability in PC12 cells," Neurochemistry International, vol. 40, no. 4, pp. 361-369, 2002.

[21] Z. Xu, D. Cawthon, K. A. McCastlain et al., "Selective alterations of transcription factors in MPP+-induced neurotoxicity in PC12 cells," NeuroToxicology, vol. 26, no. 4, pp. 729-737, 2005.

[22] J.-Y. Choi, C.-S. Park, D.-J. Kim et al., "Prevention of nitric oxide-mediated 1-methyl-4-phenyl-1,2,3,6-tetrahydropyridineinduced Parkinson's disease in mice by tea phenolic epigallocatechin 3-gallate," NeuroToxicology, vol. 23, no. 3, pp. 367-374, 2002.

[23] T. Dehmer, J. Lindenau, S. Haid, J. Dichgans, and J. B. Schulz, "Deficiency of inducible nitric oxide synthase protects against MPTP toxicity in vivo," Journal of Neurochemistry, vol. 74, no. 5, pp. 2213-2216, 2000.

[24] M. Di Nottia, M. Masciullo, D. Verrigni et al., "DJ-1 modulates mitochondrial response to oxidative stress: Clues from a novel diagnosis of PARK7," Clinical Genetics, 2016.

[25] Y. Saito, Y. Akazawa-Ogawa, A. Matsumura et al., "Oxidation and interaction of DJ-1 with 20 S proteasome in the erythrocytes of early stage Parkinson's disease patients," Scientific Reports, vol. 6, Article ID 30793, 2016.

[26] D.-K. Kim, M. A. Beaven, J. M. Kulinski et al., "Regulation of reactive oxygen species and the antioxidant protein DJ-1 in mastocytosis," PLoS ONE, vol. 11, no. 9, Article ID e0162831, 2016.

[27] Y. Kitamura, M. Inden, Y. Kimoto et al., "Effects of a DJ-1binding compound on spatial learning and memory impairment in a mouse model of Alzheimer's disease," Journal of Alzheimer's Disease, vol. 55, no. 1, pp. 67-72, 2016.

[28] L. A. Greene and A. S. Tischler, "Establishment of a noradrenergic clonal line of rat adrenal pheochromocytoma cells which respond to nerve growth factor," Proceedings of the National Academy of Sciences of the United States of America, vol. 73, no. 7, pp. 2424-2428, 1976.

[29] L. Zhang, W. Ding, H. Sun et al., "Salidroside protects PC12 cells from $\mathrm{MPP}^{+}$-induced apoptosis via activation of the PI3K/Akt pathway," Food and Chemical Toxicology, vol. 50, no. 8, pp. 25912597, 2012.

[30] S. Guo, E. Bezard, and B. Zhao, "Protective effect of green tea polyphenols on the SH-SY5Y cells against 6-OHDA induced 
apoptosis through ROS-NO pathway," Free Radical Biology and Medicine, vol. 39, no. 5, pp. 682-695, 2005.

[31] C. J. Choong and H. Mochizuki, "Gene therapy targeting mitochondrial pathway in Parkinson's disease," Journal of neural transmission, pp. 10-1007, 1996.

[32] M. Soll, O. Bar Am, A. Mahammed et al., "Neurorescue by a ROS Decomposition Catalyst," ACS Chemical Neuroscience, vol. 7, no. 10, pp. 1374-1382, 2016.

[33] X. Wang and C. Hai, "Novel insights into redox system and the mechanism of redox regulation," Molecular Biology Reports, vol. 43, no. 7, pp. 607-628, 2016.

[34] S. C. Lu, "Glutathione synthesis," Biochimica et Biophysica Acta, vol. 1830, no. 5, pp. 3143-3153, 2013.

[35] Q. Zhou, B. Chen, X. Wang et al., "Sulforaphane protects against rotenone-induced neurotoxicity in vivo: Involvement of the mTOR, Nrf2, and autophagy pathways," Scientific Reports, vol. 6, Article ID 32206, 2016.

[36] M. Todorovic, S. A. Wood, and G. D. Mellick, "Nrf2: a modulator of Parkinson's disease?” Journal of Neural Transmission, vol. 123, no. 6, pp. 611-619, 2016.

[37] M. Ahuja, N. A. Kaidery, L. Yang et al., "Distinct Nrf2 signaling mechanisms of fumaric acid esters and their role in neuroprotection against 1-Methyl-4-Phenyl-1,2,3,6-Tetrahydropyridineinduced experimental parkinson's-like disease," Journal of Neuroscience, vol. 36, no. 23, pp. 6332-6351, 2016.

[38] C. A. Massaad, T. M. Washington, R. G. Pautler, and E. Klann, "Overexpression of SOD-2 reduces hippocampal superoxide and prevents memory deficits in a mouse model of Alzheimer's disease," Proceedings of the National Academy of Sciences of the United States of America, vol. 106, no. 32, pp. 13576-13581, 2009.

[39] A. Wajda, J. Łapczuk, M. Grabowska et al., "Nuclear factor E2-related factor-2 (Nrf2) expression and regulation in male reproductive tract," Pharmacological Reports, vol. 68, no. 1, pp. 101-108, 2016.

[40] D. Guan, Y. Su, Y. Li et al., "Tetramethylpyrazine inhibits CoCl2-induced neurotoxicity through enhancement of Nrf2/GCLc/GSH and suppression of HIF1 $\alpha /$ NOX2/ROS pathways," Journal of Neurochemistry, vol. 134, no. 3, pp. 551-565, 2015.

[41] K. Bahmed, E. M. Messier, W. Zhou et al., "DJ-1 modulates nuclear erythroid 2-related factor-2-mediated protection in human primary alveolar type II cells in smokers," American Journal of Respiratory Cell and Molecular Biology, vol. 55, no. 3, pp. 439-449, 2016.

[42] E. Vázquez-Mayorga, Á. G. Díaz-Sánchez, R. K. Dagda et al., "Novel Redox-dependent Esterase activity (EC 3.1.1.2) for DJ1: Implications for Parkinson's disease," International Journal of Molecular Sciences, vol. 17, no. 8, article no. 1346, 2016.

[43] Y. Tan, L. Wu, D. Li, X. Liu, J. Ding, and S. Chen, "Methylation status of DJ-1 in leukocyte DNA of Parkinson's disease patients," Translational Neurodegeneration, vol. 5, no. 1, article no. 5, 2016.

[44] M. E. Díaz-Casado, E. Lima, J. A. García et al., "Melatonin rescues zebrafish embryos from the parkinsonian phenotype restoring the parkin/PINK1/DJ-1/MUL1 network," Journal of Pineal Research, vol. 61, no. 1, pp. 96-107, 2016. 


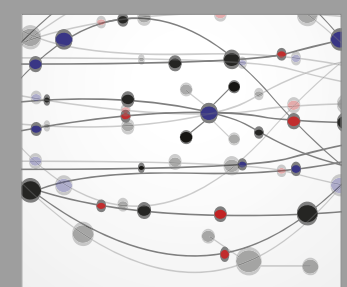

The Scientific World Journal
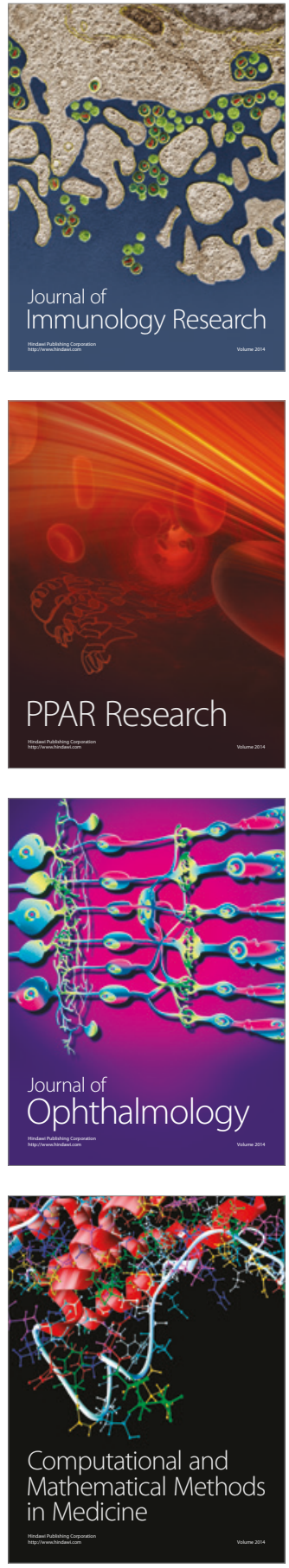

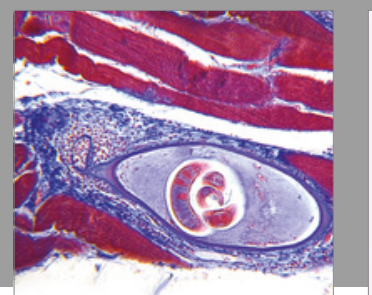

Gastroenterology Research and Practice
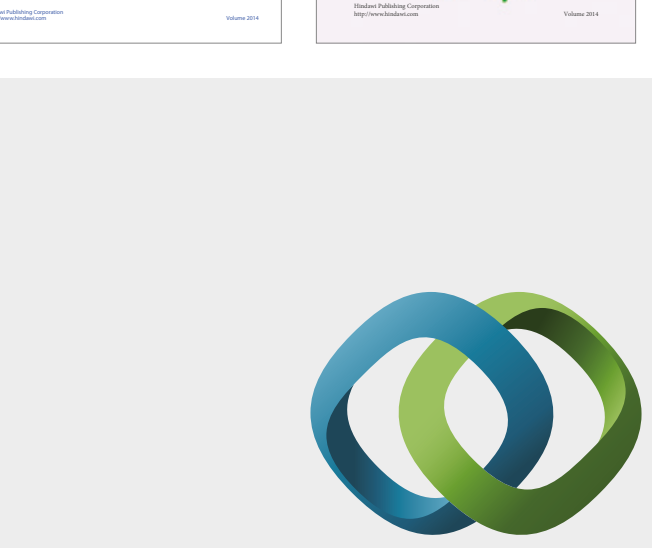

\section{Hindawi}

Submit your manuscripts at

https://www.hindawi.com
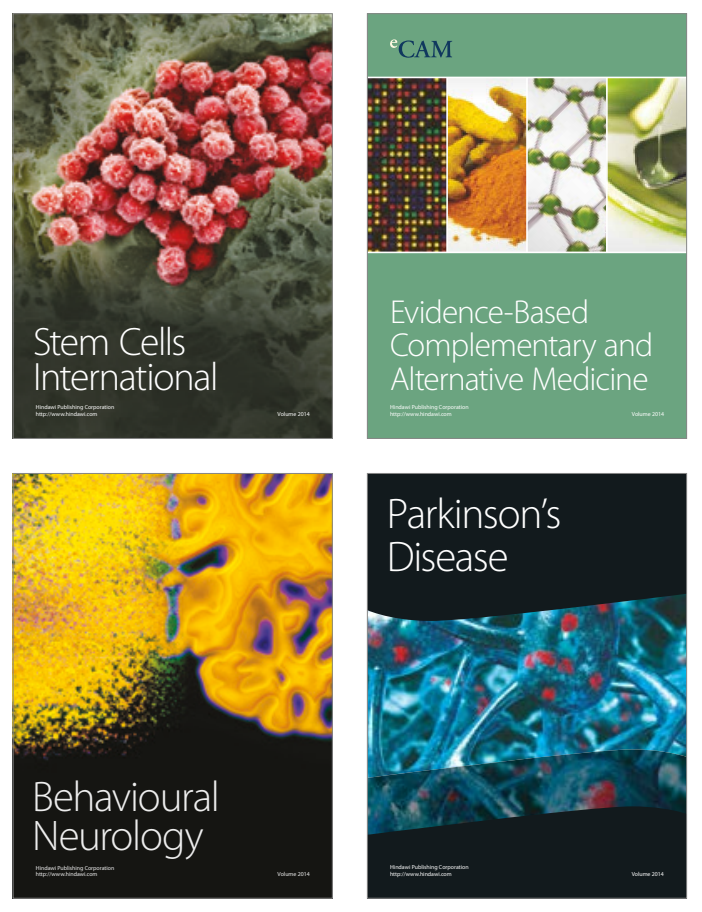
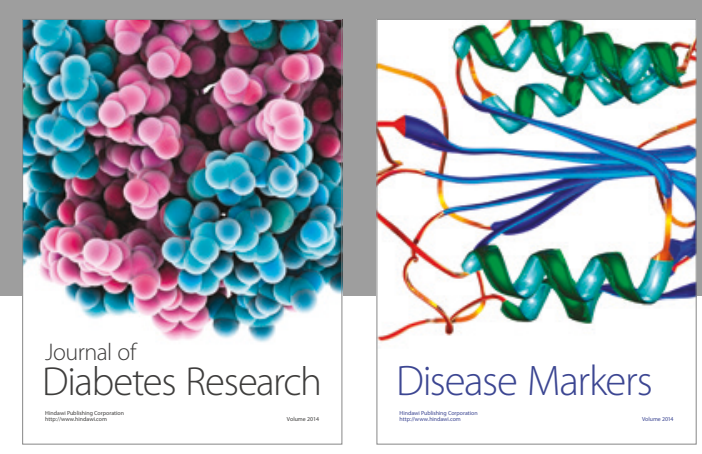

Disease Markers
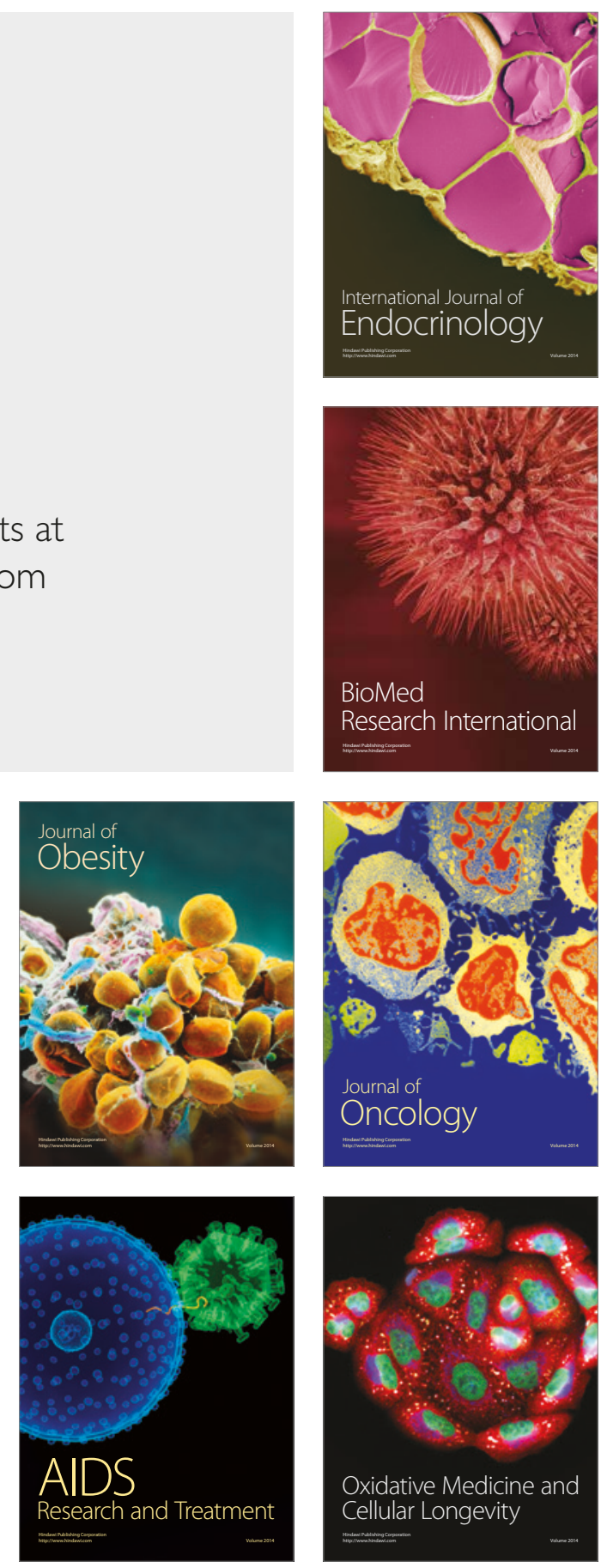